\title{
Doing Less Before It's Done Unto You: Reshaping Workflows for Efficiency Before the Wolf Is at the Door
}

THIS ARTICLE IS NOT SO MUCH about "what we can stop doing" as it is an example of how planning, change management, and clear priorities can mitigate the impact of budget cuts. With budget disasters already upon us, this might seem an exercise in closing the barn door after the horse's position has been eliminated. Yet, let's face it: what we are going through now is not the last economic "downturn" we will experience in our careers. Somebody once defined insanity as doing the same thing over and over and expecting the results to change; this article will suggest some different ways of coping with the next financial collapse.

I work for the University of Wyoming (UW), the only four-year institution of higher learning in the state. Our president likes to say "we're not just the flagship, we're the entire fleet." As a part of that fleet, I direct the American Heritage Center (AHC), the university's manuscript repository, rare books library, and university archives. We are independent of the university libraries; the Dean of Libraries and I both report to the Provost. We are among the largest and most heavily used nongovernmental repositories in the United States. ${ }^{1}$ While our single largest area of collections is Wyoming and the Rocky Mountain West, we collect nationally in a select handful of topical areas. ${ }^{2}$

Wyoming is one of the few states not completely crushed during the still enduring recession, but, during this current fiscal year, the university, like every other state agency, was forced to reduce its budget by 10 percent. That reduction was passed on to all university units. This hit was to the public portion of our budget; my unit depends for 55 percent of its resources on private funds, and our private endowment income was down 20 percent during the same year. Did we have to make cuts? Yes.

1. Our manuscripts holdings total approximately 75,000 cubic feet. We serve between 6,000 and 8,000 researchers annually, on and off site. Our single largest set of researchers are undergraduates at UW, but we annually see researchers from all 50 states and approximately a dozen foreign nations.

2. Many repositories at land grant institutions collect nationally in a handful of topics. For example: Minnesota (social welfare, history of computing, immigration, African American authors), Texas (media professionals, mathematics, literary figures, film makers, popular music, performing arts), Ohio State (polar exploration, cartoon art, theater), Illinois-Urbana (professional organizations-such as $\mathrm{OAH}$, fraternities, marching bands, advertising, 3d Armored Division), Wisconsin (mass communication, social action, film and theater, labor), Michigan (radicalism, transportation, Revolutionary War, U.S. cultural and political history to 1920). 
But before I briefly enumerate those cuts, let me note that, as soon as we knew the state budget was in trouble, our associate director, and our business manager, and I met to draw up emergency plans regarding possible personnel reductions. We sketched scenarios based on AHC budget reductions of 5 percent, 10 percent, and 20 percent and prioritized the impact that such cuts would have on our staffing. We also prioritized cuts to programs and activities, based on a conviction that we had to do everything possible to protect our core services. So several months before we knew of the 10 percent cut in public funds or the 20 percent reduction of endowment income, we had a plan for the most difficult scenarios.

As it turned out, we eliminated two positions out of a total of 24 . We reduced our nonsalary (or "programs") budget by 29 percent. That meant eliminating or reducing several noncore activities, including our annual staff retreat, our speakers' bureau, and, for the first time, beginning to charge for our traveling exhibits; it also meant drastic cuts in our travel grants, teaching grants, ${ }^{3}$ and office supplies; and it meant eliminating one of our two annual newsletters. While FY11 saw no further reductions in public funding, our endowment income decreased another 7 percent. But the planning we did in the spring of 2009 still served to guide our decisions in responding to that additional reduction.

Despite the tightening of the economic noose, we began or continued several innovative projects aimed at making better use of our existing, if then shrinking, resources. This approach to the management of our repository began long before the wolf was at the door, and it will continue long after he leaves. It has turned out that introducing efficiencies during relatively good times permitted us to continue innovating during very lean times. It has also bought us difficult-to-quantify goodwill from the university's administration. So what we stopped doing and why began long before the financial crisis.

First, some additional background. From the mid-1950s until about 1990, the AHC was a pariah within the archival profession because of the rapacious and at times unethical behavior of its 30+-year director, one of the last of a breed of collectors who believed they were entitled to anything they could get and who were much more interested in acquisition than in providing access to what was acquired. ${ }^{4}$ Although a succeeding decade of professional archivists had ended all questionable practices and placed substantial resources into processing and reference, when I arrived in 2002 I found 85,000 cubic feet of manuscript collections, with no collecting

3. Our "Innovative Teaching and Research Grants" primarily provide funds for UW faculty to develop new courses built around AHC primary sources. See http:/ / ahc.uwyo.edu/eduoutreach/trgrants [accessed 27 August 2010].

4. For details of the "Gressley Era," see Mark Shelstad, "Collecting and Mediation at the University of Wyoming," paper presented to the Fall 2003 Midwest Archives Conference Meeting (Oct. 24, 2003). 
focus, and with the AHC far behind its peers in percentages of manuscript collections cataloged online. ${ }^{5}$ By number of collections, the figure was 20 percent; by volume of collection, the figure was 24 percent. $^{6}$

We were hardly alone in having a backlog of intellectually inaccessible material. In 2004 across the United States, backlogs represented a third of the collections of two-thirds of repositories. ${ }^{7}$ But just because everyone else was doing it was, as my mother was always fond of pointing out, no good reason for us to do it, too. So within six months of my arriving at the Center, we began two major projects that represented significant workflow and perspective changes: one was to quadruple the speed of our processing, which we accomplished in 12 months through application of "More Product, Less Process" (MPLP) practices; ${ }^{8}$ the other was to begin analyzing our holdings from top to bottom, with the goal of creating a formal, public collecting policy and of applying that policy both retroand prospectively.

The changes I am going to describe were successful in part because they were based on strategic plans to which every employee at the AHC contributed. ${ }^{9}$ Thus, in the taxonomy presented by Michael Fox elsewhere in this issue, there was a fair degree of ownership or buy-in from the beginning. I see the purpose of achieving employee buy-in as a combination of two perspectives:

(1) "The leader who can take the role of a facilitator blends his or her role of visionary decisive leader with that of listening and empowering leader." 10

(2) "Many managers seek consensus, which is a determination of what the group wants.... Leaders, by contrast, do not seek consensus. They build it by persuading others to share their goals and their dreams." ${ }^{11}$

5. The online catalog is at http://uwcatalog.uwyo.edu [accessed 27 August 2010].

6. Either was below the ARL mean of $46 \%$ : Judith M. Panitch, Special Collections in ARL Libraries: Results of the 1998 Survey (Washington DC: ARL, 2001), 83. Depending on whether the number of collections or the volume of collections was considered, by 2004 the AHC had at least partially processed $66 \%$ or $84 \%$ of its collections, respectively. These figures actually compare well to the special collections units at the United States' elite Associated Research Libraries: Panitch, Special Collections in ARL Libraries, 99.

7. Mark A. Greene and Dennis Meissner, "More Product, Less Process: Revamping Traditional Archival Processing," American Archivist 68, no. 2 (Fall/Winter 2005): 210-13.

8. Greene and Meissner, "More Product, Less Process," 208-63. The approach to processing 20thcentury collections recommended in this article is also commonly referred to as "minimal processing" and "Greene-Meissner."

9. The strategic plans are available at http://ahc.uwyo.edu/about/policies.htm [accessed 27 August 2010].

10. Thomas L. Moore, "Facilitative Leadership: One Approach to Empowering Staff and Other Stakeholders." Library Trends 53 (Summer 2004): 231.

11. Brooke E. Sheldon, Leaders in Libraries: Styles and Strategies for Success (Chicago: American Library Association, 1991), 39. 
A second contributor to the success of these changes was that we were able to gradually change some personnel as well—part luck, part design, we replaced those individuals least comfortable with change with other employees who for the most part were new to the profession and not wedded to the "old" ways. Plus, I would like to think I assisted in the success in four ways: one was by being willing and able to give extended rationale for the changes; ${ }^{12}$ another was by consistently communicating not only the plan ${ }^{13}$ but the achievement of benchmarks along the way to completion. ${ }^{14} \mathrm{~A}$ third way was to find frequent occasions to tell our employees how much of a difference the changes were making in the eyes of our university administration and our profession.

And to digress slightly, I meet monthly with the Provost, and one purpose is to keep him apprised of progress in areas of specific concern to the administration, such as improving access to our collections, reassessing our collecting regimen, and continuing to expand the number of undergraduate courses and students we worked with annually. His direct feedback made it clear the work we were doing was improving our standing and stature in his and the President's eyes. The Provost also arranged to have me make two separate presentations to the biweekly meetings of the academic deans and directors, from whom I also received direct approval for the AHC's evolution. I am fairly certain that many archivists who complain about their resource allocators not appreciating or understanding them do not take the initiative to consistently educate their administrators.

Returning from that digression, the fourth way I believe I assist in the success of our changes is by doing my best to very publicly acknowledge that the AHC's success was the result of the dedication and expertise of our faculty and staff, rather than of my direction. It is vital for leaders to look "out the window, not in the mirror, to apportion credit for success." ${ }^{15}$ The manner of praise most visible to the faculty and staff was through my columns in the AHC's newsletters and annual report, received by all our employees but also, of course, by all major academic

12. "Many organisations seem to be defined by their processes, rather than using them as a means to an end. So they end up using totally inappropriate vehicles and fail to move forward. Processes are vital, but, in constantly changing competitive landscapes, they must be as agile and flexible as the people they serve. People can only be expected to react flexibly if they are helped to understand the purpose behind what they are being asked to do." Margaret Lloyd and Sheridan Maguire, "The Possibility Horizon," Journal of Change Management 3 (2002): 153.

13. As Ed Holly, a library administrator at the University of North Carolina, noted, some leaders "think they are great communicators, and they understand where they believe they are leading their organizations - but the people who are trying to do what the leader wants done, either don't understand it or are frustrated because they feel that they don't know what the two or three major things are." Quoted in Sheldon, Leaders in Libraries, 11.

14. "Creating short-term wins as a way to motivate employees is critical during a long change effort.... One must plan for and create visible performance improvements. Employees involved in those improvements should be recognised. Without specific important and visible short-term wins, people may give up and default to change resister status." Lloyd and Maguire, "The Possibility Horizon," 154.

15. Jim Collins, "Level 5 Leadership: The Triumph of Humility and Fierce Resolve," Harvard Business Review 83 (July/Aug. 2005): 141, 142. 
administrators at UW, all state legislators, our collection and financial donors, and other interested parties.

The creation and maintenance of a formal and public collection development policy began with collection analysis. ${ }^{16} \mathrm{AHC}$ faculty and staff were assigned to a series of task forces, each lasting approximately six months and each focused on one or more topical collecting areas. ${ }^{17}$ Each task force was charged with: analyzing the quantity and quality of AHC holdings in its assigned topical areas; determining the location and holdings of other repositories in the United States in those same areas; analyzing use records for materials; recommending a specific collecting policy for each of the topics and, based on that policy, extant collections at AHC for deaccessioning and appraisal guidelines for retained and yet to be acquired collections.

The recommendations from each task force were forwarded to the AHC's department heads for further discussion and (usually) revision. The full collection development policy was presented for comment to the university's deans and academic unit directors as well as being posted to the faculty discussion list (exactly two comments were received). Finally, the revised draft was forwarded to the university's Provost for review and approval, after which it was made public on our Web site. Since being made public, I have been contacted by a handful of colleagues to tell me they had come across the policy on the Web and found it useful for their own collection development work.

The collection analysis and development of collecting policy took a full five years, during which we decided that, even at four times the original speed, processing our backlog was too slow an approach if we were to "unhide" our hidden collections within a reasonable timeframe. While new funding can, as Michael Fox notes, conflict with or bypass existing programs and priorities, we were able to secure grants to directly support our strategic goals. So, with funding assistance from NHPRC, we began a three-year project to (1) create collection-level catalog records for every unprocessed collection; (2) quadruple the number of EAD finding aids we had online; (3) reappraise and deaccession as warranted every collection of ten cubic feet or larger that did not fit within our emerging collecting policy.

The grant gave us the means to assess all 2,000 of our still unprocessed collections and to further reduce our cataloging and processing backlog by reappraising more than 400

\footnotetext{
16. See our formal collecting policy, 15 October 2008 , available online at http:/ / ahc.uwyo.edu/documents/about/administration/AHC\%20Collecting\%20Policy\%20_3_\%20rev\%20_2_.pdf [accessed 27 August 2010]. The document section, "How This Collection Development Policy Was Created," details the process.

17. AHC archivists have faculty status. At the time, we also employed four paraprofessionals, all doing professional-level work but without the advanced degrees necessary for faculty rank. These paraprofessionals were part of the three-person task forces.
} 
collections and deaccessioning about 75 percent of those (totaling over 10,000 cubic feet). The total from the time of my arrival to the time of revising this paper is over 500 collections totaling over 15,000 cubic feet. Readers paying very close attention may notice that when I arrived at the AHC we had 85,000 cubic feet; we currently have 75,000 cubic feet, but we deaccessioned during that period 15,000 feet. How to account for the 5,000 cubic foot discrepancy? It derives from two facts: not all the deaccessioned collections have been physically transferred out of the repository yet; we have continued to acquire new collections, some of which were fairly large. We also reached a point, by 2009 , where we could return to processing collections that had now been cataloged, prioritizing them primarily (though not exclusively) on the collections' level of use by researchers. Other prioritizing factors include expected use for new collections, political considerations (VIP donors, for example), or the desire to show a potential donor the completed finding aid for a related collection in hopes of acquiring his or her new collection.

We continued to process at the accelerated MPLP rate and also implemented major alteration of our accessioning workflow, which now includes creation of a preliminary catalog record for every new collection, as well as a skeletal EAD finding aid; in such a manner, we can never again be susceptible to a backlog of hidden collections. We have, in addition, made alterations to our Reference workflow and, even more important perhaps, to the working relationship among Reference, Processing, and Accessioning - to mitigate the impact of minimal processing on the work of serving both on-site and long-distance researchers. For example, a reference request for a cataloged but unprocessed collection of some size and little organization might trigger immediate processing, or it might instead lead to a rudimentary box list by a student working for accessioning. On the other hand, requests for small collections (less than 2 cubic feet) generally result in Reference archivists or student pages creating proto-finding aids, which are passed on to Processing. ${ }^{18}$ This also included placing a notice on the Web page that contained the link to the catalog search page, noting the varying levels of arrangement and description of our collections. ${ }^{19}$

We also wanted to ensure that our hard-won collecting policy became prospective in its application so that our holdings would continue to develop and improve. As Gerry Ham noted in the 1990s, "By fashioning well-focused and achievable collecting policies and paying greater attention to planned acquisition, the better archival collecting agencies have developed systematic and efficient field collecting programs to identify potential collections, contact their custodians, evaluate their material's worth, and negotiate for its transfer." ${ }^{.20}$ Yet we had no dedicated acquisi-

18. See the section on "Reference" in Mark A. Greene, "MPLP: It's Not Just for Processing Anymore," American Archivist 73, no. 1 (Spring/Summer 2010): 182-91.

19. http://ahc.uwyo.edu/usearchives/default.htm [accessed 27 August 2010].

20. F. Gerald Ham, Selecting and Appraising Archives and Manuscripts (Chicago: Society of American Archivists, 1993), 37. 
tion or field archivist position, and no prospect of creating one. So, instead, every faculty member altered his or her job description such that 5 percent of his or her time was reallocated from an original activity to performing acquisition activities. Each individual was assigned one or more topical areas from our collecting policy. ${ }^{21}$

Because few of our archivists had either education or experience in acquisition or appraisal, we brought in the SAA Advanced Appraisal workshop (which I developed and teach) and the SAA Donor Relations workshop (developed and taught by Herbert Hartsook of the University of South Carolina). Nor were our archivists alone in this lacuna in their professional knowledge. Jeannette Bastian, in her study of "Teaching Appraisal in an American (U.S.) Archives Program," says,

The study identified only seven programs out of a possible 57 in U.S. library schools and history departments that offer a separate appraisal course. In the majority of these programs, appraisal is often taught as a substantial component of an introduction or advanced introduction course. In the advanced introduction syllabi examined by the study, appraisal comprised as much as $18 \%$ of the entire semester. The study also found that of the actual appraisal courses offered, there was no one reading that was common to them all, and that while all courses generally taught similar content, there were only a few topic areas taught across all seven courses.

It is little wonder, then, that we had to create our own process for creating an appraisal cadre.

I have come to think of appraisal largely in the same broad terms as Dennis Meissner and I came to view processing - it had to become much faster, less precise, tailored to each collection, and with the goal of making more and more collections available to researchers. The foundation of the process, paraphrasing Terry Cook about macro appraisal, is that an inspection of records is the last thing that happens during an appraisal; the first is a thoughtful assessment of the activities of the records creator

21. Jeannette Allis Bastian, "Teaching Appraisal in an American (U.S.) Archives Program," Archival Science 5 (2005): 373. My workshop teaching of appraisal hews closely to Bastian's recommendation for pedagogy on this subject (374): "The task of the appraisal educator is to convey a way of looking at records, an appraisal mindset, and then to give students a variety of tools through which to implement that mindset. Once the appropriate appraisal stage is set and the tools laid out, a judicious use of case studies offers a further step, a way to synthesize, to problem solve, and to actualize." In other words, I do present workshop participants with a variety of lenses through which to view appraisal in theory, as well as a case study exercise to explore the relationship of that theory to practice. See also Jeannette Bastian and Elizabeth Yakel, "'Are We There Yet?' Professionalism and the Development of an Archival Core Curriculum in the United States," Journal of Education for Library and Information Science, 46, no. 2 (Spring 2005): 95-114. 
against the repository's acquisition priorities. ${ }^{22}$ Those priorities can be identified at the level of the creator and, in the case of high-priority creators, by series. ${ }^{23}$

Collecting policies, in essence, define certain appraisal decisions in advance. Rather than having to physically examine every collection offered, the archivist will know ahead of time what sorts of collections to decline to be able to spend time instead soliciting others. Moreover, for certain types of creators, such as congressional offices and businesses, we have predefined the series to be acquired as well. Acquisition decisions will not be made case by case serendipitously or intuitively; ${ }^{24}$ they will instead be based on well-planned policies that approach the documentation universe broadly. These steps reduce the amount of time spent appraising, but only on the premise that the goal is not to ensure every "interesting" document is identified and preserved. As Gerry Ham noted fifteen years ago, “Today’s information-laden world has lessened the value of any single set of records; the documents may be unique but the information is usually not." 25 This decentralized acquisition process has only been truly under way since January of 2010, but it has already begun, slowly, to bear fruit.

To further assist both the archivists and the process, we formulated a procedure for sharing solicitation letters and of discussing acquisition issues en masse during biweekly acquisition committee meetings. As part of performing an appraisal, the archivists are asked to begin developing a cataloging worksheet, an electronic document that is forwarded to our accessioning department (and from there to processing).

All of these steps were received quite well by the university administration. While I cannot prove a direct quid pro quo, I can say that, as we were completing our collecting policy and deaccession project, the university agreed to pony up half a million dollars to refurbish our building's security system, and another half a million to replace our dry-pipe sprinkler system — both were original to the building in 1993. The security system was breaking down and no replacement parts were available; the sprinkler pipes were misinstalled originally, leading to a growing number of erosion holes causing periodic decompression of the system. My predecessors

22. Terry Cook, "Mind Over Matter: Toward a New Theory of Archival Appraisal," ed. Barbara L. Craig, The Archival Imagination: Essays in Honour of Hugh Taylor (Ottawa: Association of Canadian Archivists, 1992), 53.

23. For appraisal by creator, see Mark A. Greene and Todd J. Daniels-Howell, "Documentation with 'an Attitude': A Pragmatist's Guide to the Selection and Acquisition of Modern Business Records," in Records of American Business, ed. James M. O’Toole (Chicago: SAA, 1997), 161-229; for appraisal of series within a high-priority set of records creators, see Mark A. Greene, "Appraisal of Congressional Papers at the Minnesota Historical Society: A Case Study," Archival Issues 19, no. 1 (1994): 31-44.

24. For a recent survey of Canadian archivists, $75 \%$ stated that they used, at least in part, "intuition" to make appraisal decisions. Barbara L. Craig, "Doing Archival Appraisal in Canada: Results from a Postal Survey of Practitioners' Experience, Practices, and Opinions," Archivaria 64 (2007): 21, 26-27.

25. F. Gerald Ham, Selecting and Appraising Archives and Manuscripts (Chicago: Society of American Archivists, 1993), 72. 
had been lobbying for these improvements for the better part of a decade. While it is perfectly true that, when the funds were finally allocated, the state was in relatively flush times, there was certainly no guarantee that the AHC would see any largesse. The AHC's achievements have also led to recognition within our profession. At the August 2010 meeting of the Society of American Archivists, the AHC was presented with SAA's Distinguished Service Award, the highest distinction available to an archival repository in the United States. ${ }^{26}$

There is yet one more way in which we have elected to make existing or shrinking resources more efficient, so that we give our researchers more of what they want rather than the same amount or less. This change, unlike the others I have described, was implemented during the budget crisis rather than before it. The change has to do with digitization. A precondition for our change in approaches to scanning was a decision made in 2003 to ensure that digitization was as stable and essential a function of our repository as were reference and processing, rather than continuing to expect - as we had up to that time - the activity to survive from grant to grant. We did this, in large part, by shifting some personnel resources to permanently staff both the management and hands-on work of digitization; ${ }^{27}$ this stage was another example of the hard choices necessary even without the pressure of budget cuts.

Given the demand by our researchers for more and more digitized material, and given the proposition - which I have presented in several previous venues ${ }^{28}$ - that researcher use is the purpose of all archival effort, we must adopt approaches to scanning that dramatically increase how much we can make accessible for the same or even fewer resources. In particular, we need to develop an approach that will finally permit us to tackle digitization of our extraordinary masses of textual collections. As one archivist has noted, "We cannot avoid tackling our paper based collections because they are too hard, too big, too expensive to touch." ${ }^{29}$

Why have we avoided digitizing all but "gems" from our paper collections? How

26. See www.archivists.org/governance/handbook/section12-service.asp [accessed 27 August 2010].

27. Briefly, we allotted a larger percentage of workload for our digital programs manager to digitization planning, and to do that we shifted what had been that position's responsibility for university archives to one of our processing archivists. In addition, we converted what had been a paraprofessional processing position into a scanning technician position. We believed the tradeoff was possible in part because our remaining processors, using MPLP, were working so much more efficiently.

28. See, particularly, "The Power of Archives: Archivists' Values and Value in the Post-Modern Age," American Archivist 72, no. 1 (Spring/Summer 2009): 17-41. Originally presented as SAA Presidential address 2008, and also available online at www.archivists.org/governance/presidential/GreeneAddressAug08.pdf [accessed 27 August 2010] and "Existential Archives: Looking To the Value Propositions of Archives and Special Collections," ARL/CNI Forum, "An Age of Discovery: Distinctive Collections in the Digital Age," October 2009, Washington, D.C., available online at www.arl.org/bm $\sim \mathrm{doc} /$ mm09greeneremarks.pdf [accessed 27 August 2010].

29. Joshua Ranger, "More Bytes, Less Bite: Cutting Corners in Digitization," unpublished paper presented at the fall 2006 Midwest Archives Conference symposium. 
can we turn from desperately explaining to patrons why scanning is too expensive to do on a large scale and finally start giving our users what they most want-more and more research material online? It turns out that it is not that hard; it simply requires abjuring item-level metadata.

We have been inculcated in the belief that we have to do item-level metadata, which is exorbitantly expensive for collections of any size. One of the earliest objections raised against MPLP was that it ran directly counter to the growing need to identify individual items for digitization..$^{30}$ Instead, I argue that this focus on item-level digitization is a signal failing of many of our Web-based projects.

There is a related fallacy that we really need to predefine and describe items during processing to facilitate digitization of items. This is wrong for the same reason that believing individual calendaring of documents is essential to support researchers is wrong-it is simply not that difficult to find items if the description of series or files is done well. To take an example from the realm of visual materials, it is not necessary to have cataloged every photograph in a vertical file or a record group to find one good one of Henry Ford with Walt Disney. All that is necessary is a file unit labeled Ford and Disney, or even a series labeled Ford with VIPs; while the latter will require some minutes to discover the "perfect" image, it is far less time than would have been required to process every item.

Not only is there nothing to prevent us from organizing and describing digitized (or born-digital) material at the file or even series level, except our own fascination with individual documents, using group metadata is more in keeping with the rest of archival practice. A recent OCLC report admonished, "Stop obsessing about items. Everything that is digitized does not need to be painstakingly described. Archival control distinguishes organic collections from description of distinct books and museum objects. Let's embrace that collection management strategy as well as the standards and practices of managing collections and hierarchies, not necessarily items." ${ }^{31}$

Repositories as varied as the AHC, University of Wisconsin Oshkosh, and the Smithsonian Archives of American Art provide file-level metadata to speed provision of digitized material to researchers. ${ }^{32}$ If we can do this much, one archivist

\footnotetext{
30. Here and following is largely taken from Greene, "MPLP: It’s Not Just for Processing Anymore," 192-94.

31. Ricky Erway and Jennifer Schaffner, Shifting Gears: Gearing Up to Get Into the Flow (Dublin, OH: OCLC, 2007), 6 .

32. Archives of American Art, available online at www.aaa.si.edu/collectionsonline/ [accessed 27 August 2010]. Also see a thoughtful assessment of how to approach a mass digitization project, "Extending the Reach of Southern Sources Proceeding to Large-Scale Digitization of Manuscript Collections," Final Grant Report Prepared by the Southern Historical Collection, University Library, The University of North Carolina at Chapel Hill, for the Andrew W. Mellon Foundation, June 2009, available online at www.lib.unc.edu/mss/archivalmassdigitization/Extending_the_Reach.pdf [accessed 27 August 2010].
} 
wrote, "and without a vast infusion of funds, good.... Is it perfect? No, but remember, the perfect is sometimes the enemy of the good." ${ }^{33}$ Another archivist echoed him by arguing, as MPLP would, that "every dollar spent to make [online] collections perfect is a dollar we're not spending to get another collection on-line and to a larger potential audience." ${ }^{34}$ Folder or series metadata can be placed in standard image and document delivery systems, and/or shortcut even further by linking folders of material to their place in online finding aids; the latter provides the most and best context for the material ${ }^{35}$ - and, as a bonus, permits us to provide more of what our users want.

In addition to dramatically streamlining metadata, another, compatible, step aimed at providing more digitized material for the same or less resources is to abandon the "digitize once" philosophy, long the accepted standard. Digitizing every item to maximum resolution not only dramatically eats up storage space, it wastes time on the front end because relatively few of the scans will in fact ever be requested by patrons as a high-density file. Instead, at the AHC, we have begun scanning at lower resolutions, with the understanding that, if/when a researcher needs a higher resolution copy, we will rescan (the lone exception to this approach is preservation digitization, which we have begun to do for our nitrate negatives, since the negatives will be destroyed after scanning).

In conclusion, coping with resource reductions is an unfortunate but real part of overall program management — indeed, perhaps more than management, leadership, because it often entails making choices between two "good" alternatives and communicating the importance of that choice to the archives staff, resource allocators, and constituents. Or, to second Michael Fox, it is a matter of leading change. When our budget crisis was clear, we reported that to our employees as quickly as matters of confidentiality permitted. Possibly of most importance, we tried to make clear what our strategy and priorities were-namely protection of core functions. But the ideal is to envision and achieve change before it is forced from outside one's unit.

Sadly, I realize that many of my colleagues who administer programs have been hit with budget reductions so large as to force cuts in vital services; sometimes there is no alternative. But I do believe three things related to resource management. First is that proactively implementing workflow efficiencies and resource reallocation can (doesn't always, but can) impress resource allocators to an extent that, when

33. Max J. Evans, "The Archival Time Machine: A Closet Engineer Looks at Our Profession," NEA Newsletter 31, no. 1 (Jan. 2004): 8.

34. Ranger, "More Bytes, Less Bite."

35. Max J. Evans, "Archives of the People, By the People, For the People," American Archivist 70 (Fall/ Winter 2007): 391-93. 
they come, budget cuts might not be as severe as they might be for units that have not demonstrated active evolution of their processes and services.

Second, as soon as budget reductions become even a reasonable possibility, planning how to absorb those cuts will assist the archives in the end, compared with having to scramble to make decisions once reductions are announced. And, third, I reject the tactic used by some administrators (including some I have worked for) of trying to blackmail your resource allocators by threatening to abolish the repository's most popular or important activities in hopes that cuts can be restored. Not only does the tactic not work in true budget emergencies, it hurts the very people we should care most about assisting_our patrons.

Making choices about what to continue and what to discontinue, or about how to use existing or reduced resources more efficiently, is a necessary part of administration, whether or not budget cuts loom. Before we are forced to do less with less, we should try to do more with the same; that will reduce the impact on our researchers when we really do have fewer resources. It also helps to clarify what is most important among our activities and services, and it gives us a better chance to protect those, to a certain degree, when the wolf is at the door.

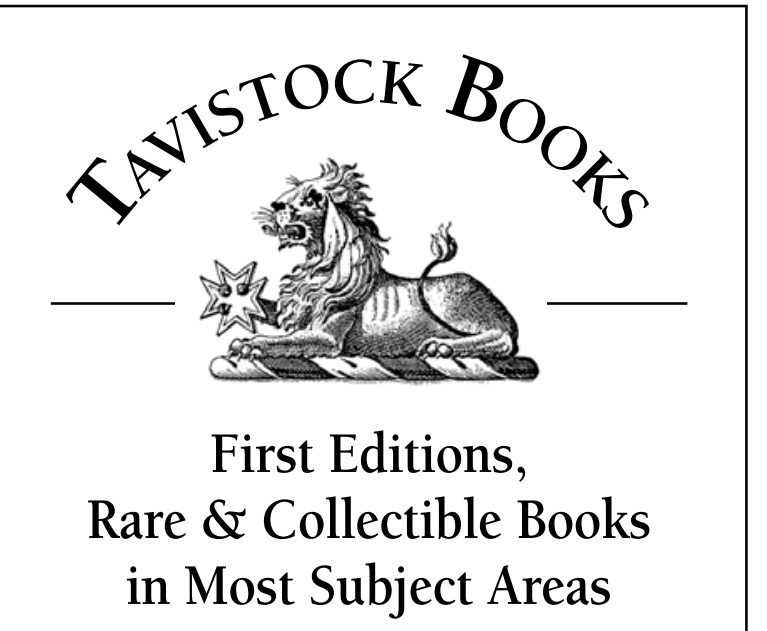

\section{WWW.TAVBOOKS.COM}

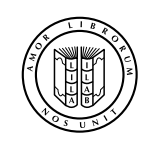

1503 WEBSTER STREET • ALAMEDA, CALIFORNIA 94501 T: $510.814 .0480 \bullet F: 510.814 .0486 \bullet v j z @ t a v b o o k s . c o m$ 